\title{
Dynamique des chromosomes / Chromosome dynamics
}

Centre interdisciplinaire de recherche en biologie (CIRB)

Olivier Espéli

\section{(2) OpenEdition \\ Journals}

Édition électronique

URL : https://journals.openedition.org/annuaire-cdf/16132

DOI : 10.4000/annuaire-cdf. 16132

ISBN : 978-2-7226-0572-5

ISSN : 2109-9227

\section{Éditeur}

Collège de France

\section{Édition imprimée}

Date de publication : 30 décembre 2020

Pagination : 651

ISBN : 978-2-7226-0516-9

ISSN : 0069-5580

\section{Référence électronique}

Olivier Espéli, « Dynamique des chromosomes / Chromosome dynamics », L'annuaire du Collège de France [En ligne], 118 | 2020, mis en ligne le 01 avril 2021, consulté le 22 août 2022. URL : http:// journals.openedition.org/annuaire-cdf/16132; DOI : https://doi.org/10.4000/annuaire-cdf.16132 


\title{
RÉSEAUX DE SYSTÈMES ÉVOLUTIFS / NETWORK IN EVOLUTIONARY SYSTEMS
}

\author{
Responsable : Anton CROMBACH
}

\section{Publication}

Verd B., Clark E., Wotton K.R., Janssens H., JiméneZ-Guri E., Crombach A. et JAEGER J., «A damped oscillator imposes temporal order on posterior gap gene expression in Drosophila », PLOS Biology, vol. 16, $\mathrm{n}^{\mathrm{o}}$ 2, 2018, e2003174, [première version DOI : 10.1101/068072], DOI : 10.1371/journal.pbio.2003174.

\section{DYNAMIQUE DES CHROMOSOMES / CHROMOSOME DYNAMICS}

\author{
Responsable : Olivier ESPÉLI
}

\section{RECHERCHE}

Page web : https://www.college-de-france.fr/site/en-cirb/espeli.htm.

\section{PuBlications}

EL SAYYED H. et ESPÉLI O., « Mapping E. coli Topoisomerase IV binding and activity sites », Methods in Molecular Biology, vol. 1703, 2018, p. 87-94, DOI : 10.1007/978-1-4939-74597_6.

Leh H., Khodr A., Bouger M.-C., Sclavi B., Rimsky S. et Bury-Moné S., «Bacterialchromatin structural proteins regulate the bimodal expression of the locus of enterocyte effacement (LEE) pathogenicity island in enteropathogenic Escherichia coli », MBio, vol. 8, $\mathrm{n}^{\mathrm{o}}$ 4, 2017, DOI : 10.1128/mBio.00773-17.

DemarRe G., Prudent V. et EspéLI O., « Imaging the cell cycle of pathogen E. coli during growth in macrophage », Methods in Molecular Biology, vol. 1624, 2017, p. 227-236, DOI : 10.1007/978-1-4939-7098-8_17.

VICKRIDGE E., PLANCHENAULT C. et EsPÉLI O., « Revealing sister chromatid interactions with the loxP/Cre recombination assay », Methods in Molecular Biology, vol. 1624, 2017, p. 29-37, DOI : 10.1007/978-1-4939-7098-8_3.

Vickridge E., Planchenault C., Cockram C., Junceda I.G. et Espéli O., « Management of E. coli sister chromatid cohesion in response to genotoxic stress », Nature Communications, vol. 8, 2017, 14618, DOI : 10.1038/ncomms14618.

Muller H., Scolari V.F., Agier N., Piazza A., Thierry A., Mercy G., DescorpsDeclere S., LaZar-Stefanita L., Espeli O., Llorente B., Fischer G., Mozziconacci J. et Koszul R., "Characterizing meiotic chromosomes' structure and pairing using a designer sequence optimized for Hi-C », Molecular Systems Biology, vol. 14, nº 7, 2018, e8293, DOI : 10.15252/msb.20188293. 